Original Article

\title{
INTERACTION OF COPPER OXIDE NANOPARTICLES WITH BOVINE SERUM ALBUMIN BY SPECTROSCOPIC STUDIES
}

\author{
SUJA ABRAHAM*, VELLAICHAMY PARTHASARATHY
}

Department of Physics, Hindustan Institute of Technology and Science, India

Email: sujaabrahamthuthiyil@gmail.com

Received: 20 Jan 2018 Revised and Accepted: 22 Mar 2018

\begin{abstract}
Objective: Since structural changes of adsorbed protein are necessary for cellular uptake of nanoparticles (NPs) it is of prime importance to know about structural changes of bovine serum albumin (BSA) when it interacts with CuO NPs-a potential new antitumor drug.

Methods: CuO NPs prepared by sol-gel technique were characterized by x-ray diffraction (XRD) and tunneling electron microscope (TEM) techniques. The conformational changes induced by CuO NPs on BSA were studied by various spectroscopic techniques such as steady state and time-resolved fluorescence measurements. The changes in fluorescence emission parameters such as fluorescence intensity, fluorescence emission maximum and lifetimes of fluorescent residues in BSA were studied.

Results: XRD analysis showed the average particle size as $32 \mathrm{~nm}$. The TEM micrograph showed particles of different size varying from 10 to $45 \mathrm{~nm}$. Fluorescence quenching was confirmed due to a decrease in fluorescence intensity of CuO NPs-BSA complex. The analysis of lifetime measurements indicated BSA contained two tryptophan (trp) residues that fluoresced in different environments. Static quenching mechanism was confirmed by
\end{abstract} time-resolved measurements when BSA interacted with CuO NPs.

Conclusion: Minor structural changes of BSA protein were observed during the interaction studies.

Keywords: Protein, Copper oxide nanoparticles, Spectroscopy, Structural changes

(C) 2018 The Authors. Published by Innovare Academic Sciences Pvt Ltd. This is an open access article under the CC BY license (http://creativecommons.org/licenses/by/4.0/) DOI: http://dx.doi.org/10.22159/ijpps.2018v10i5.24877

\section{INTRODUCTION}

Nanotechnology holds a huge promise for the design and development of many types of novel products with its potential medical applications on early disease detection, treatment and prevention [1-4]. NPs large functional surface area allows them to bind absorb and carry other compounds [5]. Copper compounds have been used to treat cancer and several diseases for thousands of years [6]. In vitro and in vivo studies showed that metal oxide NPs can directly kill tumor cells [7]. CuO NPs have many advantages such as simple preparation procedure, long-term stability, and anticancer properties and showed a strong affinity to bind blood carrier proteins [8, 9]. BSA is a good model to study protein conformational changes due to its wide range of physiological functions [10], an ideal protein for intrinsic fluorescence measurements [11], wellcharacterized structure and property and readily undergoes conformational changes $[12,13]$.

The NP-protein interactions give rise to the formation of protein corona which has a major impact on NPs cellular uptake. When protein structure of an adsorbed protein is lost uptake of NPs by the cell will get inhibited whereas unfolding of an adsorbed protein facilitates cellular uptake of NPs due to access receptors on cell surface. Thus structural changes of adsorbed protein are necessary for cellular uptake of NPs [14]. NPs exhibit unique behaviour in human body, but there is only a limited knowledge of how NPs interact with cells and proteins. Since blood circulatory system is the most probable treatment administration option for NPs into the human body, it is important to investigate how adsorption of blood proteins on NPs will affect the protein's secondary structure [15]. Spectroscopic techniques can be used as a powerful tool to accomplish this need. Therefore, in the present study interaction of $\mathrm{CuO}$ NPs with BSA was studied by spectroscopic techniques. To the best of our knowledge lifetime measurements by TCSPC technique of BSA$\mathrm{CuO}$ complex is reported for the first time.

\section{MATERIALS AND METHODS}

\section{Chemicals}

BSA was purchased from Sigma-Aldrich, USA. Copper chloride and sodium hydroxide were purchased from SD fine chemicals, India.

\section{Preparation of CuO NPs}

$0.5 \mathrm{M} \mathrm{CuCl}_{2} .6 \mathrm{H}_{2} \mathrm{O}$ was dissolved in de-ionized water in a $250 \mathrm{ml}$ conical flask with constant stirring. A very little amount of citric acid was added to the above solution [16]. The solution mixture was heated at $80^{\circ} \mathrm{C}$ with continuous stirring. Then a required quantity of separately prepared $\mathrm{NaOH}$ solution was added slowly into the above heated solution under vigorous stirring. The colour of the solution turned to black from blue which confirmed the formation of $\mathrm{CuO}$. The addition of $\mathrm{NaOH}$ solution was stopped after the formation of large amount of black precipitate. The obtained black precipitate was collected by a centrifuge. The obtained mass was washed several times with ethanol and de-ionized water to remove impurities. The product was further dried at $80{ }^{\circ} \mathrm{C}$ for $12 \mathrm{~h}$ in oven. The dried product was grinded well using mortar and pestle and then it was annealed at $300^{\circ} \mathrm{C}$ to obtain crystalline $\mathrm{CuO}$ Nano powder.

\section{Stock preparation and interaction of BSA with CuO NPs}

Among the prepared stock solutions of BSA and $\mathrm{CuO}$ NPs, CuO NPs were subjected to ultrasonic vibration for $20 \mathrm{~min}$. The mixture of BSA with various concentrations of $\mathrm{CuO}$ NPs was homogenized and kept for 30 min for incubation. The emission spectra were taken in the range $310-420 \mathrm{~nm}$ at an excitation wavelength of $290 \mathrm{~nm}$ [17]. Double distilled water was used for interaction studies. All measurements were performed at room temperature.

\section{Characterization}

XRD

The structure of $\mathrm{CuO}$ was confirmed using Brucker K 8600 X-ray diffractometer in the $2 \theta$ range of $20^{\circ}$ to $80^{\circ}$.

\section{TEM}

The particle size of the prepared nano-sized $\mathrm{CuO}$ was estimated with the help of JEOL JSM 5610 LV tunnelling electron microscope.

\section{Steady-state fluorescence measurements}

JASCO FP-8600 spectrofluorometers was used for fluorescence measurements with excitation wavelength $290 \mathrm{~nm}$. The excitation 
slit width $2.5 \mathrm{~nm}$, emission slit width $2 \mathrm{~nm}$ and scan rate 500 $\mathrm{nm} /$ min were maintained constant for all measurements.

\section{Time-resolved fluorescence measurements}

Picosecond time-correlated single photon counting (TCSPC) spectrometer was used for fluorescence lifetime measurements. The excitation source is the tunable Ti-sapphire laser (Tsunami, Spectra Physics, USA).

\section{RESULTS AND DISCUSSION}

\section{XRD analysis}

The structure of $\mathrm{CuO}$ has been investigated using XRD profile. Fig. 1 shows XRD pattern of CuO NPs. All the existing diffraction peaks in XRD profile are in good agreement with standard JCPDS data (File no. 05-661). The diffraction peaks also confirmed the monoclinic structure of $\mathrm{CuO}$. The peaks are broad due to nano size effect. The average particle size was calculated as $32 \mathrm{~nm}$ using Scherrer formula.

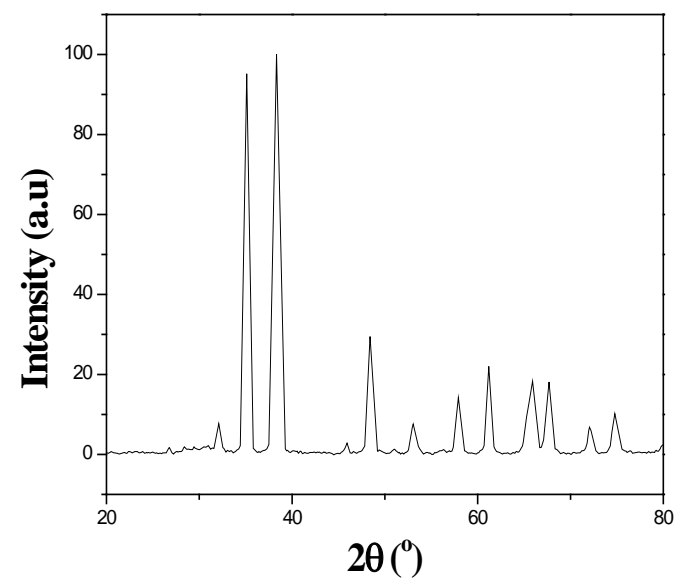

Fig. 1: XRD pattern of CuO NPs

\section{TEM study}

The size and morphology of CuO NPs have been examined using TEM. The nanoparticles are spherical in shape as shown in fig. 2 . The TEM micrograph has shown particles of different size approximately from $10 \mathrm{~nm}$ to $45 \mathrm{~nm}$. The TEM result also coincides with the estimated particle size in XRD analysis.

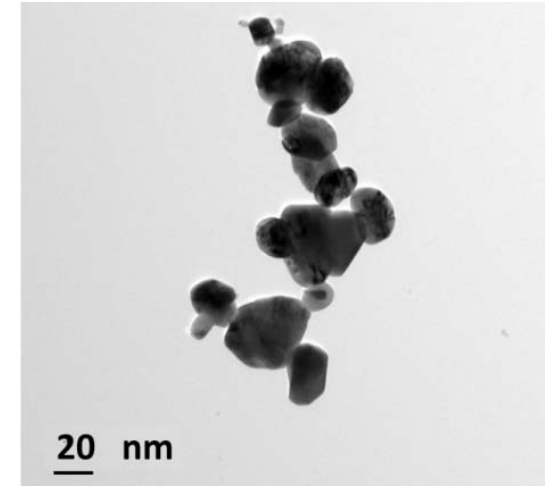

Fig. 2: TEM micrograph of CuO NPs

\section{Steady-state fluorescence analysis}

The intrinsic fluorescence spectra of BSA and BSA-CuO NP complex at excitation wavelength $290 \mathrm{~nm}$ are shown in fig. 3. BSA-metal oxide NPs interaction was reported earlier at this same excitation wavelength $[18,19]$. Fig. 3 clearly shows that the emission maximum of BSA is at $343 \mathrm{~nm}$ and fluorescence spectrum of native BSA is different than that of BSA-CuO NP complex. With increasing concentrations of CuO NPs in BSA a gradual decrease in fluorescence intensity without any shift in emission maximum of BSA was observed. This result is consistent with the studies in which it was reported that the binding abilities of $\mathrm{TiO}_{2} \mathrm{NPs}$ and Ag-doped $\mathrm{TiO}_{2} \mathrm{NPs}$ with serum albumins showed that both $\mathrm{TiO}_{2} \mathrm{NPs}$ and Ag-doped $\mathrm{TiO}_{2} \mathrm{NPs}$ quench fluorescence without any shift in emission maxima [20, 21]. The fluorescence intensity of BSA gradually decreased for increasing concentrations of $\mathrm{CuO}$ NPs indicating $\mathrm{CuO}$ NPs are responsible for quenching the fluorescence of BSA. The decreased fluorescence intensities of CuO NP-BSA conjugates suggests interactions between $\mathrm{CuO}$ NPs and BSA. A concentration-dependent quenching of intrinsic fluorescence intensity of BSA, suggests that $\mathrm{CuO}$ NPs binds to BSA.

Increased concentrations of Copper (I) oxide NPs and gold NPs in BSA resulted in a decrease in fluorescence intensity due to quenching $[22,13]$. Quenching of the intrinsic fluorescence of BSA with a blue shift in emission maximum was reported during the interaction studies of BSA with increasing concentrations of $\mathrm{ZnO}$ NPs [23], Cu NPs [24, 25], silver NPs [26] and colloidal capped CdS NPs [27]. The addition of $\mathrm{ZnO}$ NPs of different concentration with BSA resulted in a small red shift with a change in maximum emission intensity suggesting the occurrence of fluorescence quenching process [19]. The interaction of BSA with $\mathrm{Al}_{2} \mathrm{O}_{3} \mathrm{NPs}$ did not show any concentration-dependent fluorescence quenching [28].

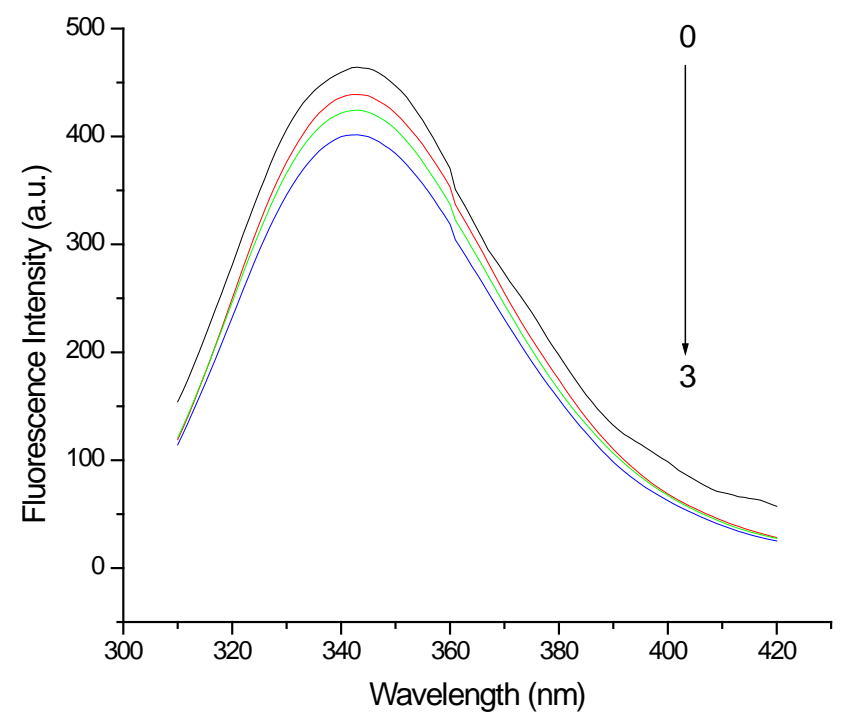

Fig. 3: Fluorescence spectra of BSA at different concentrations of CuO NPs $\left(0,6,9\right.$ and $\left.12 \times 10^{-8} \mathrm{M}\right)$ 


\section{Time-resolved fluorescence analysis}

The exponential decay curves of BSA and BSA-CuO NP complex are shown in fig. 4. The fluorescence decay of BSA was fitted with two exponentials, $\mathrm{T}_{1}=6.50 \mathrm{~ns}$ and $\mathrm{T}_{2}=2.46 \mathrm{~ns}$ and is consistent with the studies that lifetimes of trp fluorescence are often multiexponential [29]. The changes in a lifetime, give information about the local environment of the trp-residues [30]. The marked difference between two lifetimes indicated that one of the trp residues in a protein may be relatively exposed whereas other trp residue appears to be deeply buried inside the protein [31].

The fluorescence lifetime of both trp residues in BSA decreased when interacted with different concentrations of $\mathrm{CuO}$ NPs. The decrease was more prominent for lifetime $T_{2}$. Similar results were observed with decrease in fluorescence lifetime when BSA interacted with $\mathrm{TiO}_{2} \mathrm{NPs}$ and silver NPs [32, 33]. While increasing concentrations of CuO NPs in BSA, lifetime of BSA-CuO NP complex gradually increased for lifetime $\mathrm{T}_{1}$ whereas an increase and then decrease in fluorescence lifetime was observed for lifetime $\mathrm{T}_{2}$ (fig. 4 and table 1). Overall there was no significant change in lifetime of both trp residues compared to that of native BSA. For static quenching, complex formation will not disturb fluorescence lifetime of trp residues in BSA [12]. Therefore, present results clearly indicated static quenching was consistent in this reaction process. This result is consistent with fluorescence quenching rate constant studies in which static quenching mechanism was observed when BSA interacted with Cu NPs [24, 25] and CuO NPs [34]. Static quenching mechanism was confirmed by time-resolved measurements when BSA interacted with colloidal $\mathrm{ZnO}$ nps [35], $\mathrm{SnO}_{2}$ nps [32], $\mathrm{TiO}_{2}$ nps [36] and no significant change in average lifetime of trp residues with gold NPs [37].

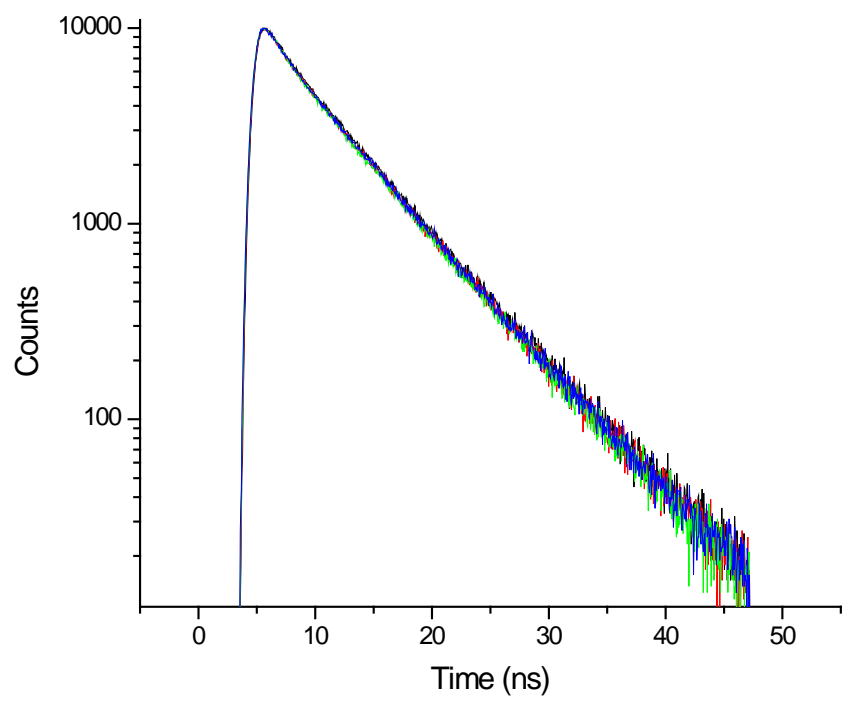

Fig. 4: Time-resolved fluorescence decay of BSA at different concentrations of CuO NPs $\left(0,6,9\right.$ and $\left.12 \times 10^{-8} \mathrm{M}\right)$

\section{Conformational changes of BSA-CuO NP complex}

The protein NP interaction result in considerable changes of the structure and function of proteins [38, 39]. When different concentrations of CuO NPs interacted with BSA a gradual reduction of BSA fluorescence intensity was observed. Protein conformational changes will generate some alterations in fluorescence intensity and disturb microenvironment around trp residues [40, 41]. Thus it is concluded that conformational changes occurred during this interaction studies. There was no significant change in fluorescence lifetime of both trp residues in BSA when interacted with CuO NPs indicating static quenching process. For static quenching, fluorescence lifetime will not get disturbed [18]. In the present study, a decrease in fluorescence intensity and a small change in lifetimes (fig. 3, fig. 4 and table 1) implies minor conformational changes induced by $\mathrm{CuO}$ NPs on BSA. Conformational changes were observed when BSA interacted with Copper I oxide NPs [15], Cu NPs [25], ZnO NPs [23], colloidal ZnO $\mathrm{NPs}$ [35], $\mathrm{TiO}_{2} \mathrm{NPs}[20]$ and tin oxide NPs [32].

Table 1: Emission wavelengths, corresponding fluorescence intensities, lifetime of BSA and BSA with different concentrations of CuO NPs

\begin{tabular}{|c|c|c|c|c|}
\hline Sample & Emission maximum (nm) & Fluorescence intensity (a. u.) & Lifetime $T_{1}$ (ns) & Lifetime $\mathrm{T}_{2}$ (ns) \\
\hline BSA & 343 & 464 & 6.50 & 2.46 \\
\hline $\mathrm{BSA}+6 \times 10^{-8} \mathrm{M}, \mathrm{CuO}$ NPs & 343 & 438 & 6.38 & 2.12 \\
\hline $\mathrm{BSA}+9 \times 10^{-8} \mathrm{M} \mathrm{CuO}$ NPs & 343 & 424 & 6.40 & 2.37 \\
\hline $\mathrm{BSA}+12 \times 10^{-8} \mathrm{M} \mathrm{CuO} \mathrm{NPs}$ & 343 & 401 & 6.42 & 2.32 \\
\hline
\end{tabular}

\section{CONCLUSION}

CuO NPs were synthesized by sol-gel technique. XRD analysis showed the average particle size as $32 \mathrm{~nm}$. The TEM micrograph showed particles of different size varying from 10 to $45 \mathrm{~nm}$. Based on fluorescence spectroscopic studies of BSA and BSA-CuO NP complex following conclusions were made. Fluorescence quenching was confirmed due to a decrease in fluorescence intensity of $\mathrm{CuO}$ NPs-BSA complex. The analysis of lifetime measurements indicated that no significant change in both lifetimes $\mathrm{T}_{1}$ and $\mathrm{T}_{2}$ of trp residues in BSA, when interacted with different concentrations of $\mathrm{CuO}$ NPs, confirmed static quenching was dominant in this reaction process.
The two lifetimes indicated that BSA contained two trp residues, longer lifetime indicated that trp residue is buried inside hydrophobic interior of protein and shorter lifetime indicted trp residue is closer to the quencher. BSA-CuO NP conjugate made changes in BSA fluorescence emission parameters probably confirmed minor conformational changes in the structure of BSA.

\section{AUTHORS CONTRIBUTIONS}

Suja Abraham-Principal Investigator-did steady state fluorescence analysis, time-resolved fluorescence analysis and prepared the manuscript. 
Vellaichamy Parthasarathy-Co-investigator-Synthesized CuO NPs, did XRD analysis and TEM study.

\section{CONFLICT OF INTERESTS}

There is no conflict of interest between authors

\section{REFERENCES}

1. Seigneuric R, Markey L, Nuyten DSA, Dubernet C, Evelo CTA, Finot E, Garrido C. From nanotechnology to nanomedicine: applications to cancer research. Curr Mol Med 2010;10:640-52.

2. Renu K. Nanoparticles: a promising drug delivery approach. Asian J Pharm Clin Res 2018;11:30-5.

3. Jessy S, Ipshita M. Recent advances in nanocarrier based therapeutic and diagnostic tools for colorectal cancer. Int J Curr Pharm Res 2015;7:9-16.

4. Jyotibala B. Application of nanotechnology in food technology and targeted drug therapy for prevention of obesity: an overview. J Crit Rev 2017;4:7-11.

5. Swati JS, Praseetha PK, Sakthivel G. Targetted therapy for breast cancer cells by herbal drug formulations of iron oxide nanoparticles. Asian J Pharm Clin Res 2016;9:347-53.

6. Hajra KM, Liu JR. Apoptosome dysfunction in human cancer. Apoptosis 2004;6:691-704.

7. Vinardell MP, Mitjans M. Antitumor activities of metal oxide nanoparticles. Nanomaterials 2015;5:1004-21.

8. Wang Y, Zi XY, Su J, Zhang HX, Zhang XR, Zhu HY, et al. Cuprous oxide nanoparticles selectively induce apoptosis of tumor cells. Int J Nanomed 2012;7:2641-52.

9. Manyasree D, Kiran MP, Ravikumar R. CuO nanoparticles: synthesis, characterization and their bactericidal efficacy. Int J Appl Pharm 2017;9:71-4.

10. Olson RE, Christ DD. Plasma protein binding of drugs. Annu Rep Med Chem 1996;31:327-36.

11. Jung Se H, Choi SJ, Kim HJ. Molecular characteristics of bovine serum albumin-dextran conjugates. Biosci Biotechnol Biochem 2006;70:2064-70.

12. Lakowicz JR. Principles of fluorescence spectroscopy. $2^{\text {nd }}$ edn. Dordrecht: Kluwer Academic Publishers; 1999.

13. Shang L, Wang YZ, Jiang JG. pH-dependent protein conformational changes in albumin: gold nanoparticle bioconjugates: a spectroscopic study. Langmuir 2007;23:2714-21.

14. Fleischer CC, Christine K Payne. The secondary structure of corona proteins determines the cell surface receptors used by nanoparticles. J Phys Chem B 2014;118:14017-26.

15. Tokonami S, Shiigi H, Nagaoka T. Preparation of nanogapped gold nanoparticle array for DNA detection. Electroanalysis 2008;20:355-60.

16. Kshirsagar M, Shrivastava R, Adwani S. Preparation and characterization of copper oxide nanoparticles and determination of enhancement in critical heat flux. Therm Sci 2017;21:1233-42.

17. Sun T, Liu L, Sun Y, Tan C, Yao F, Liang X, et al. Synthesis and characterization of TiO2 nanoparticles: applications in research on the interaction of colloidal TiO2 with Human serum albumin by fluorescence spectroscopy. Anal Sci 2012;28:491-6.

18. Lakowicz JR. Principles of fluorescence spectroscopy. $3^{\text {rd }}$ edn. New York: Springer; 2008.

19. Bhunia AK, Samanta PK, Saha S, Kamilya T. ZnO nanoparticleprotein interaction: Corona formation with associated unfolding. Appl Phys Lett 2013;103:143701.

20. Kathiravan A, Renganathan R. Interaction of colloidal TiO2 with bovine serum albumin: a fluorescence quenching study. Colloids Surf A 2008;324:176-80.

21. Kathiravan A, Renganathan R, Anandan S. Interaction of colloidal AgTiO2 nanoparticles with bovine serum albumin. Polyhedron 2009;28:157-61.
22. Maity M, Pramanik SK, Pal U. Copper (I) oxide nanoparticle and tryptophan as its biological conjugate: a modulation of cytotoxic effects. J Nanopart Res 2014;16:2179.

23. Bhogale A, Patel N, Sarpotdar P, Mariam J, Dongre PM, Miotello $\mathrm{A}$, et al. Systematic investigation on the interaction of bovine serum albumin with $\mathrm{ZnO}$ nanoparticles using fluorescence spectroscopy. Colloids Surf B 2013;102:257-64.

24. Bhogale A, Patel N, Mariam J. Comprehensive studies on the interaction of copper nanoparticles with bovine serum albumin using various spectroscopies. Colloids Surf B 2014;113:276-84.

25. Latheef SAA, Chakravarthy G, Mallaiah D. Spectroscopic and computational analysis of protein binding on copper nanoparticles: an insight into ligand and nanocarrier interaction. J Appl Spectrosc 2016;83:896-902.

26. Mariam J, Dongre PM, Kothari DC. Study of interaction of silver nanoparticles with bovine serum albumin using fluorescence spectroscopy. J Fluoresc 2011;21:2193-9.

27. Jhonsi MA, Kathiravan A, Renganathan R. Spectroscopic studies on the interaction of colloidal capped CdS nanoparticles with bovine serum albumin. Colloids Surf B 2009;72:167-72.

28. Rajeshwari A, Sunandan P, Swayamprava D, Madhumita V, Chandrasekaran N, Amitava M. Spectroscopic studies on the interaction of bovine serum albumin with Al203 nanoparticles. J Lumin 2014;145:859-65.

29. Kelkar DA, Chaudhuri A, Haldar S, Chattopadhyay A. Exploring tryptophan dynamics in acid-induced molten globule state of bovine alpha-lactalbumin: a wavelength-selective fluorescence approach. Eur Biophys J 2010;39:1453-63.

30. De Llanos R, Sanchez Cortes S, Domingo C. Surface plasmon effects on the binding of antitumoral drug emodin to bovine serum albumin. J Phys Chem C 2011;115:12419-29.

31. Johansson JS. Binding of the volatile anaesthetic chloroform to albumin demonstrated using tryptophan fluorescence quenching. J Biol Chem 1997;272:17961-5.

32. Togashi DM, Ryder AG, Mahon DM, Dunne P, McManus J. Fluorescence study of bovine serum albumin and $\mathrm{Ti}$ and $\mathrm{Sn}$ oxide nanoparticles Interactions. Proc SPIE-OSA Biomed Optics 2007;6628:1605-22.

33. Voicescu M, Ionescus S, Daniel GA. Spectroscopic and coarsegrained simulation studies of BSA and HSA protein adsorption on silver nanoparticles. J Nanopart Res 2012;14:1174.

34. Esfandfar P, Falahati M, Saboury AA. Spectroscopic studies of the interaction between $\mathrm{CuO}$ nanoparticles and bovine serum albumin. J Biomol Struct Dyn 2016;34:1962-8.

35. Kathiravan A, Paramaguru G, Renganathan R. Study on the binding of colloidal zinc oxide nanoparticles with bovine serum albumin. J Mol Struct 2009;934:129-34.

36. Gao XY, Wen W, Song ZY, Zhang AP, Hao J, Huang Q. Effects of rare earth ions on the interaction between nano $\mathrm{TiO}_{2}$ and bovine serum albumin in the presence of ultrasound. Acta Phys Chim Sin 2012;28:417-22.

37. Ojha K, Chowdhury PK, Ganguly AK. Fluorescence and CD studies of protein denaturation in the presence of sub picomolar gold nanoparticles. Indian J Chem 2012;51:1561-6.

38. Monopoli MP, Aberg C, Salvati A, Dawson KA. Biomolecular coronas provide the biological identity of nanosized materials. Nat Nano 2012;7:779-86.

39. Walkey CD, Chan WC. Understanding and controlling the interaction of nanomaterials with proteins in a physiological environment. Chem Soc Rev 2012;41:2780-99.

40. Garg A, Manidhar DM, Gokara M, Malleda C, Reddy CS. Elucidation of the binding mechanism of coumarin derivatives with human serum albumin. PLoS One 2013;8:e63805.

41. Soares S, Mateus N, De Freitas V. Interaction of different polyphenols with bovine serum albumin and human salivary $\alpha$ amylase by fluorescence quenching. J Agric Food Chem 2007;55:6726-35. 